\title{
CORROSION RATE OF 1.4152 STAINLESS STEEL IN A HOT NITRATE ACID
}

\author{
${ }^{1}$ Tomasz LIPIŃSKI, ${ }^{2}$ Dariusz KARPISZ \\ ${ }^{1}$ University of Warmia and Mazury in Olsztyn, Poland, EU, tomaszlipinski.tl@gmail.com \\ ${ }^{2}$ Cracow University of Technology, Cracow, Poland, EU, dkarpisz@pk.edu.pl
}

https://doi.org/10.37904/metal.2019.911

\begin{abstract}
The construction material during corrosion processes loses its properties, it causes deterioration of functions, loses its usefulness, applicability. One of the important aggressive environments in the building as well as agricultural, chemical and energetic industry is nitrogen, from which nitric acid may be formed. Due to high economic and also a good resistance to mechanical characteristics, good weldability and corrosion the 1.4162 steel is commonly used in industry as chemical, pulp cellulose industry, oil and gas industry, building industry. The aim of the research was to determine the corrosive wear of 1.4162 steel, corrosion resistance with ferriticaustenitic microstructure using the Huey test. The tested steel contains $0.03 \% \mathrm{C}, 21.2 \% \mathrm{Cr}, 1.42 \% \mathrm{Ni}$ and $5.0 \% \mathrm{Mn}$. The samples were weighed before start of the corrosion processes and after them. Samples were kept in nitric acid $65 \%$ at temperature $332 \mathrm{~K}$. The holding times of the samples in nitric acid were 48, 96, 144, $192,240,288,336,384$ hours. The percentage of mass losses was determined by the weight method. Each sample was examined metallographically using an optical microscope and the surface roughness test using a profilometer. The test results were analyzed in order to determine the corrosion rate of steel in mm/year and $\mathrm{g} / \mathrm{m} 2$ as well as percentage mass loss and determine the corrosion resistance in this environment. After corrosion of the steel, the roughness and mass loss has increased. Then it was confirmed that as the holding time in boiling nitric acid increases, corrosive wear increases.
\end{abstract}

Keywords: Steel, stainless steel, corrosion, corrosion rate, roughness

\section{INTRODUCTION}

The first stainless steels were developed almost hundred years ago. Mainly grades this steels are ferritic, austenitic and martensitic microstructure. In the 1930's from a mistake in the melt shop in adding too much chromium to an austenitic steel were melted two-phase (ferritic-austenitic) duplex steel. High chromium and molybdenum contents provide excellent resistance to pitting and crevice corrosion. For the most part, the corrosion resistance of a welded joint is slightly lower than the parent material $[1,10]$.

Duplex stainless steel are among the most popular as construction material. They are used in a wide range of industrial applications, but their properties are continuously studied to improve the quality of properties. Low maintenance costs and very high material circulation, good environmental reasons for using will be further important arguments to enhance the selection of this steels. It is great importance to have duplex steels readily available to fabricators and end users. Because of this skilled technical support, well known its properties in different temperatures are required to widen the application areas duplex steels [2-4].

There steels are more prone than austenitic steels to precipitation of phases causing embrittlement and reduced corrosion resistance. The formation of intermetallic phases such as sigma phase occurs in the temperature range $600-950^{\circ} \mathrm{C}$ and reformation of ferrite occurs in the range $350-525{ }^{\circ} \mathrm{C}\left(530^{\circ} \mathrm{C}\right.$ embrittlement). In normal alloying, heat-treatment or welding processes the risk of embrittlement is not to high [5]. However a risk exist for example in the failure that can arise during its operation causing overheating, especially if the cooling is slow. Then heat treatment processes, 
for both solution annealing and stress relieving, is advisable at certain temperatures with subsequent rapid cooling in water [6,7]. A lot of authors report that corrosion resistance of stainless steels depends on rich chromium precipitates in microstructure [8,9].

The aim of this work is to influence the heating at $1423 \mathrm{~K}$ by 30 minutes and cooling down on air on roughness and corrosion rate in nitric acid 1.4162 lean duplex stainless steel.

\section{MATERIALS AND METHODS}

The experiment was performed with lean duplex stainless steel LDX 2101 (1.4162, X2CrNiN22-5-2, S32101).

The samples were held at a temperature $1423 \mathrm{~K}$ by 30 minutes and cooling down on air. Accordance with standard PN-EN ISO 3651-1:2004, Determination of resistance to intergranular corrosion of stainless steels. Part 1: Austenitic and ferritic-austenitic (duplex) stainless steels. Corrosion test in nitric acid medium by measurement of loss in mass (Huey test), corrosive media were represented by boiling nitric acid $\vee 65 \%$.

Before experiments, the specimens with an area of $10.4 \mathrm{~cm} 2(4 \times 1 \times 0.6 \mathrm{~cm})$ were successively polished with emery paper to roughness no more then $\mathrm{Ra}=0.35 \mu \mathrm{m}$ of, next mechanically cleaned with $95 \%$ alcohol.

The corrosion rare of the 1.4162 steel measured in $\mathrm{mm} / \mathrm{year}$ was calculated with the use of the below formula (1), but measured in $\mathrm{g} / \mathrm{m} 2$ were calculated with the use of the below formula (2):

$$
\begin{aligned}
& r_{\text {corm }}=\frac{8760 \cdot m}{s \cdot t \cdot \rho} \\
& r_{\text {corg }}=\frac{10000 \cdot m}{s \cdot t}
\end{aligned}
$$

where:

$$
\begin{aligned}
& \mathrm{t} \text { - time of treatment in a corrosive solution of boiling nitric acid [hours] } \\
& \mathrm{S} \text { - surface area of the sample }\left[\mathrm{cm}^{2}\right] \\
& \mathrm{m} \text { - average mass loss in boiling solution [g] } \\
& \rho \text { - sample density }\left[\mathrm{g} / \mathrm{cm}^{3}\right]
\end{aligned}
$$

The influence of boiling nitric acid on the 1.4162 steel corrosion resistance was investigated using weight loss. The mass of samples were measured by Kern ALT 3104AM general laboratory precision balance with accuracy of measurement $0.0001 \mathrm{~g}$.

Profile roughness parameters were analyzed according to the PN-EN 10049:2014-03 standard (Measurement of roughness average Ra and peak count RPc on metallic flat products) by the Diavite DH5 profilometer.

\section{RESULTS}

The chemical composition of the tested steel is presented in Table 1.

Table 1 Chemical composition of the tested 1.4162 steel

\begin{tabular}{|c|c|c|c|c|c|c|c|c|c|}
\hline \multicolumn{10}{|c|}{ Mean chemical compositions [wt. \%] } \\
\hline $\mathrm{C}$ & $\mathrm{Si}$ & $\mathrm{Mn}$ & $\mathrm{P}$ & $\mathrm{S}$ & $\mathrm{Cr}$ & $\mathrm{Mo}$ & $\mathrm{Ni}$ & $\mathrm{N}$ & $\mathrm{Cu}$ \\
\hline 0.03 & 0.87 & 5.0 & 0.025 & 0.010 & 21.2 & 0.64 & 1.42 & 0.20 & 0.25 \\
\hline
\end{tabular}

Real mechanical properties at ambient temperature of the based 1.4162 steel, according to PN-EN ISO 68921:2016-09 is presented in Table 2 and after corrosion test in the nitric acid at $332 \mathrm{~K}$ for $240 \mathrm{~h}$ in Table 3. 
Table 2 Mechanical properties at ambient temperature of the based 1.4162 steel

\begin{tabular}{|c|c|c|}
\hline \multicolumn{3}{|c|}{ Mechanical properties (mean from 2 tests) } \\
\hline $\mathrm{R}_{\mathrm{eH}}$ & $\mathrm{R}_{\mathrm{m}}$ & $\mathrm{A}$ \\
\hline $\mathrm{MPa}$ & $\mathrm{MPa}$ & $\%$ \\
\hline 476 & 687 & 38 \\
\hline
\end{tabular}

Table 3 Mechanical properties at ambient temperature of the based 1.4162 steel after corrosion test in the nitric acid at $332 \mathrm{~K}$ for $240 \mathrm{~h}$ for $\mathrm{t}=4.06 \mathrm{~mm}$

\begin{tabular}{|c|c|c|}
\hline \multicolumn{3}{|c|}{ Mechanical properties (mean from 3 tests) } \\
\hline $\mathrm{ReH}_{\mathrm{eH}}$ & $\mathrm{R}_{\mathrm{m}}$ & $\mathrm{A}$ \\
\hline $\mathrm{MPa}$ & $\mathrm{MPa}$ & $\%$ \\
\hline 428 & 436 & 7 \\
\hline
\end{tabular}

Before experiments, the specimens with an area of $13 \mathrm{~cm}^{2}(4 \times 1 \times 0.6 \mathrm{~cm})$ were successively polished with 800 grades emery paper to roughness $R_{a}=0.35 \mu \mathrm{m}$ of, next mechanically cleaned with $95 \%$ alcohol.

Percentage effects of corrosion time on the relative mass loss (RML) of 1.4162 steel annealed at $1423 \mathrm{~K}$ by 30 minutes and cooling down on air is presented in Figure 1, regression equation and correlation coefficient $r$ at (3).

$R M L=0.1467 \cdot t-3.7718$ and $\mathrm{r}=0.9987$

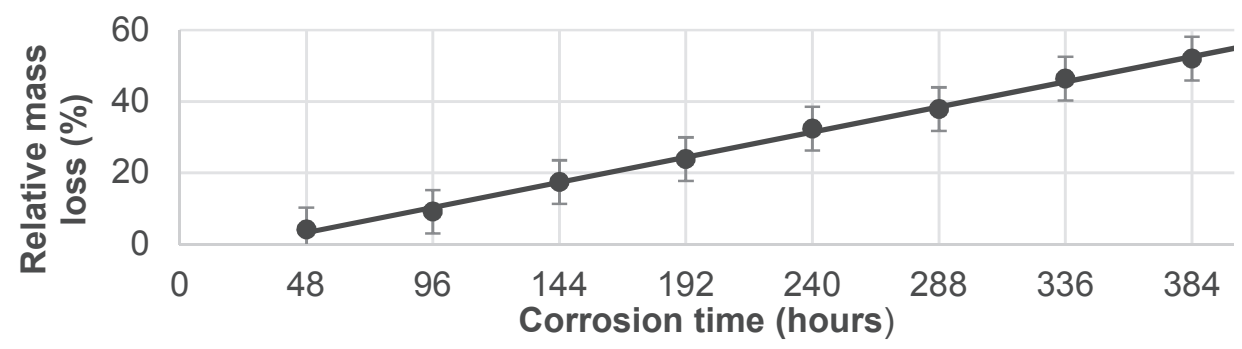

Figure 1 Percentage effects of corrosion time on the relative mass loss (RML) of 1.4162 steel annealed at $1423 \mathrm{~K}$ for 30 minutes and cooling down on air

Effects of corrosion time on the corrosion rate measured in mm per year of 1.4162 steel annealed at $1423 \mathrm{~K}$ by 30 minutes and cooling down on air is presented in Figure 2, regression equation and correlation coefficient $r$ at (4).

$r_{\text {corm }}=-0.0001 \cdot t^{2}+0.0866 \cdot t+13.098$ and $\mathrm{r}=0.9662$

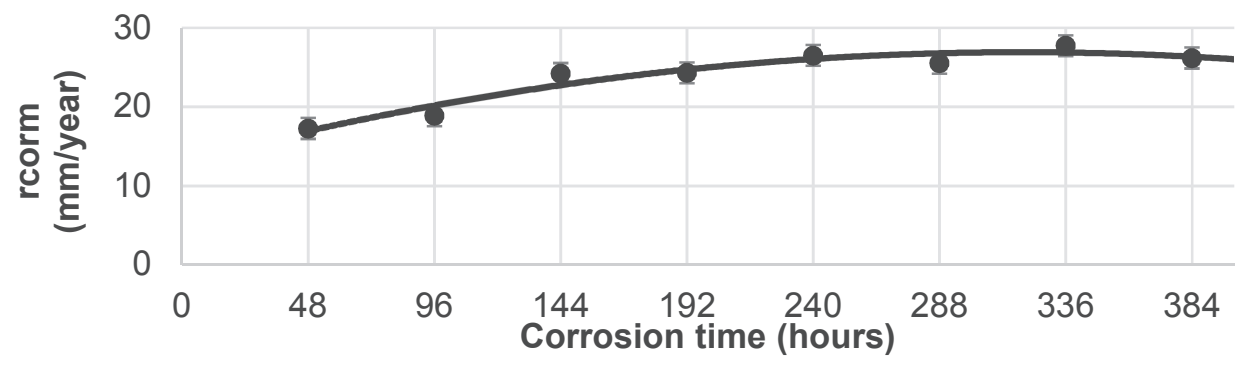

Figure 2 Effects of corrosion time on the corrosion rate measured in $\mathrm{mm}$ per year $\mathrm{r}_{\text {corm }}$ of 1.4162 steel annealed at $1423 \mathrm{~K}$ for 30 minutes and cooling down on air 
Effects of corrosion time on the corrosion rate measured in gram per $\mathrm{m}^{2}$ of 1.4162 steel annealed at $1423 \mathrm{~K}$ by 30 minutes and cooling down on air is presented in Figure 3, regression equation and correlation coefficient $r$ at (5).

$r_{\text {corm }}=-0.0001 \cdot t^{2}+0.0777 \cdot t+11.752$ and $\mathrm{r}=0.9662$

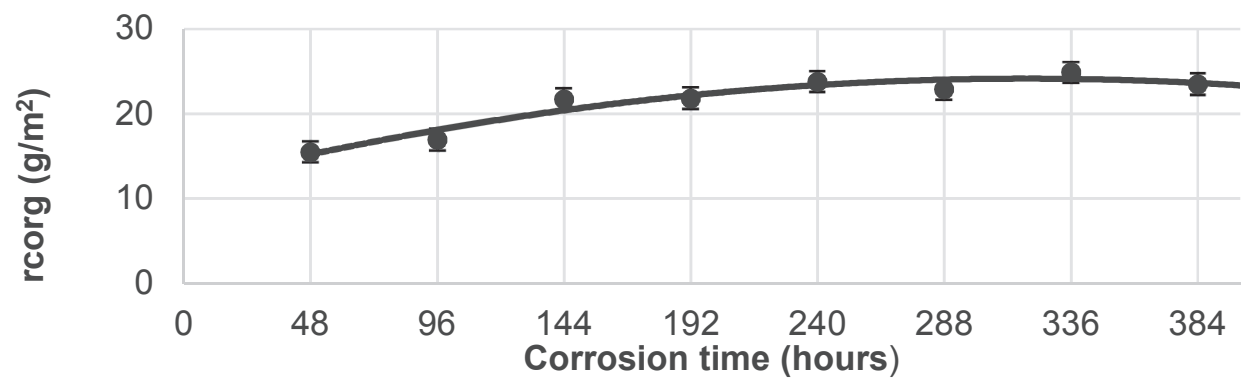

Figure 3 Effects of corrosion time on the corrosion rate measured in $\mathrm{g}$ per $\mathrm{m}^{2} \mathrm{r}_{\mathrm{corg}}$ of 1.4162 steel annealed at $1423 \mathrm{~K}$ for 30 minutes and cooling down on air

Profile roughness parameters of 1.4162 steel annealed at $1423 \mathrm{~K}$ for 30 minutes and cooling down on air for different time is presented in Figures 4, regression equation and correlation coefficient $r$ (means for 5 measutements) at (6)-(9).

$R_{a}=0.0002 \cdot t^{2}-0.0292 \cdot t+1.0555$ and $r=0.9971$

$R_{q}=0.0003 \cdot t^{2}-0.0342 \cdot t+1.557$ and $r=0.9972$

$R_{t}=0.0008 \cdot t^{2}+0.053 \cdot t-5.0484$ and $\mathrm{r}=0.9966$

$R_{p}=0.0005 \cdot t^{2}+0.0738 \cdot t-5.6804$ and $r=0.9934$

a)

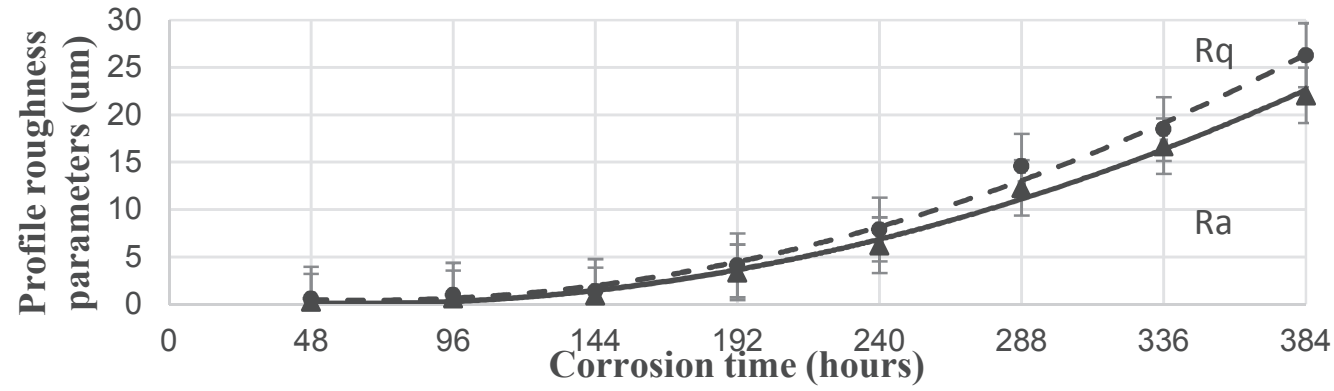

b)

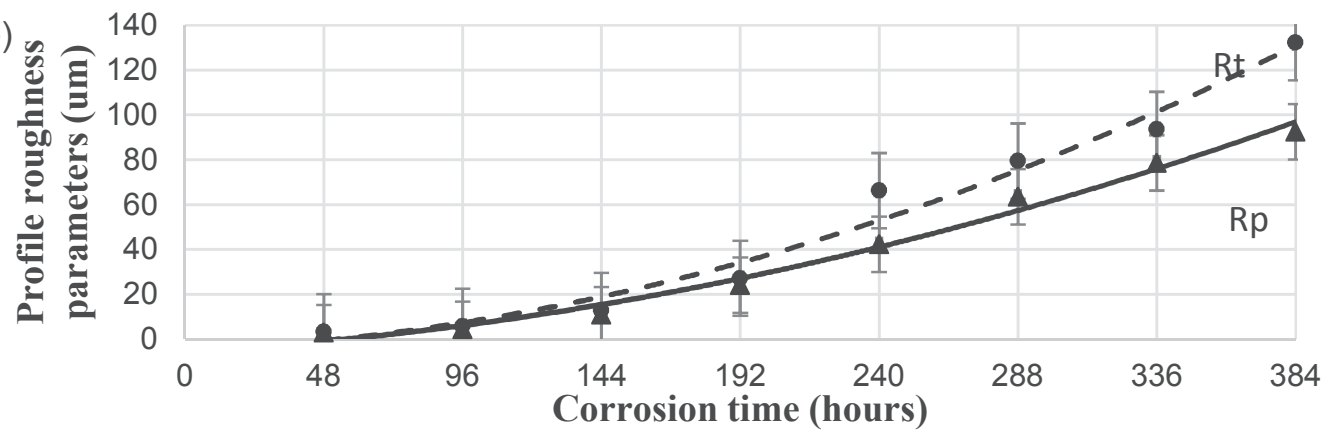

Figure 4 Profile roughness of 1.4162 steel annealed at $1423 \mathrm{~K}$ for $30 \mathrm{~min}$. and cooling down on air after corrosion tests in boiling $\mathrm{HNO}_{3}$ for different boiling time: a) $\mathrm{Ra}$ - arithmetic average of absolute values [ $\mu \mathrm{m}$ ], $\mathrm{Rq}$ - root mean squared [ $\mu \mathrm{m}]$; b) Rp - maximum peak height [ $\mu \mathrm{m}]$, Rt - Maximum Height of the Profile [ $\mu \mathrm{m}]$ 


\section{CONCLUSION}

Corrosion rate and changes in roughness 1.4162 steel as a result of exposure the $65 \%$ nitric acid at $332 \mathrm{~K}$ best reflect the second degree curves.

Up to 48 hours of soaking samples in nitric acid the corrosion rate increases slowly. In the next period up to 240 hours a linear increase in corrosion velocity was observed. After exceeding this time, the corrosion velocity oscillated around a constant size, and in the final period even slightly decreased. The first two stages are natural. In the first, the acid induces surface development, which in the second test period is invigorated. Achieving a constant corrosion rate can be explained by acid eluting of equiaxed grains.

After a time of 240 hours of the test, the samples lost about $30 \%$ of the thickness and the equalization of the yield point with the limit of tensile strength was observed. Such properties of the material should be explained by creating corrosive hollows along the grain boundaries, which not only reduce the cross-section of the material, but also create microstructural notches.

It has been confirmed that for steel LDX, roughness correlates with the rate of corrosion. Therefore, it is possible to infer about the corrosion progress based on the surface roughness.

In further investigation, the more complex methods of data analysis will be used e.g. 2D image analysis [11] and $3 D$ image analysis [12], materials science-oriented statistical methods [13-15], even enhanced by fuzzy [16-19] and Monte Carlo approach [20].

\section{REFERENCES}

[1] NOWACKI, Jerzy. Stal duplex i jej spawalność. Wydawnictwo Naukowo-Techniczne 2009.

[2] GUNN R.N., ed., Duplex Stainless Steels: Microstructure, Properties and Applications, Abington Publishing, Cambridge, United Kingdom, 1997.

[3] SZABRACKI, P. and LIPIŃSKI, T. Effect of aging on the microstructure and the intergranular corrosion resistance of X2CrNiMoN25-7-4 duplex stainless steel. Solid State Phenom. 2013, vol. 203-204, pp. 59-62.

[4] PIETRASZEK, J. and GADEK-MOSZCZAK, A. The smooth bootstrap approach to the distribution of a shape in the ferritic stainless steel AISI 434L powders. Solid State Phenom. 2013, vol. 197, pp. 162-167.

[5] ELMER, J.W., PALMER, T.A. and SPECHIT, E.D., Direct Observations of Sigma Phase Formation in Duplex Stainless Steels Using In -Situ Synchrotron X-Ray Diffraction. Metallurgical and Materials Transactions A 2007, vol. 38A, pp. 464-475.

[6] LIPIŃSKI, T. Corrosion rate of the X2CrNiMoN22-5-3 duplex stainless steel annealed at $500{ }^{\circ} \mathrm{C}$. Acta Phisica Polonica A 2016, vol. 130, pp. 993-995.

[7] HE, Y., ZHU, N., LU, X. and LI, L., Experimental and computational study on microstructural evolution in 2205 duplex stainless steel during high temperature aging. Materials Science and Engineering A 2010, vol. 528, pp. 721-729.

[8] WEI, Z., LAIZHU, J., JINCHENG, H. and HONGMEI, S. Effect of ageing on precipitation and impact energy of 2101 economical duplex stainless steel. Materials Characterization 2009, vol. 60, pp. 50-55.

[9] DEHGHAN-MANSHADI, A., SHOKOUHI, A. and HODGSON, P.D. Effect of isothermal dissolution and reprecipitation of austenite on the mechanical properties of duplex structures. Materials Science and Engineering $A$ 2010, vol. 527, pp. 6765-6770.

[10] LILJAS M., 80 Years With Duplex Steels, A Historic Review And Prospects For The Future. Outokumpu Stainless $A B$, Sweden. http://www.euro-inox.org (access date: 22.04.2019).

[11] SZCZOTOK, A., RADEK, N. and DWORNICKA, R. Effect of the induction hardening on microstructures of the selected steels. In METAL 2018: 27th Int. Conf. Metallurgy and Materials. Ostrava: TANGER, 2018, pp. 12641269. 
[12] GADEK-MOSZCZAK, A., RADEK, N., WRONSKI, S., TARASIUK, J. Application the 3D image analysis techniques for assessment the quality of material surface layer before and after laser treatment. Adv. Mat. Res. Switz. 2014, vol. 874, pp. 133-138.

[13] BARA, M., KMITA, T. and KORZEKWA, J. Microstructure and properties of composite coatings obtained on aluminium alloys. Arch. Metall. Mater. 2016, vol. 61, pp. 1107-1112.

[14] OPYDO, M., KOBYLECKI, R., DUDEK, A. and BIS, Z. The effect of biomass co-combustion in a CFB boiler on solids accumulation on surfaces of P91 steel tube samples. Biomass \& Bioenergy 2016, vol. 85, pp.61-68.

[15] RADEK, N., SZCZOTOK, A., GADEK-MOSZCZAK, A., DWORNICKA, R., BRONCEK, J. and PIETRASZEK, J. The impact of laser processing parameters on the properties of electro-spark deposited coatings. Arch. Metall. Mater. 2018, vol. 63, pp.809-816.

[16] SKRZYPCZAK-PIETRASZEK, E., PIETRASZEK, J. Phenolic acids in in vitro cultures of Exacum affine Balf. $\mathrm{f}$. Acta Biol. Cracov. Bot. 2009, vol. 51, pp. 62-62.

[17] PIETRASZEK, J. Fuzzy regression compared to classical experimental design in the case of flywheel assembly. Lecture Notes in Artificial Intelligence 2012, vol. 7267, pp. 310-317.

[18] PIETRASZEK, J., KOLOMYCKI, M., SZCZOTOK, A. and DWORNICKA, R., 2016. The fuzzy approach to assessment of ANOVA results. In ICCCI 2016: Conf. on Comp. Collective Intell. Springer, pp. 260-268.

[19] SKRZYPCZAK-PIETRASZEK, E., REISS, K., ZMUDZKI, P. and PIETRASZEK, J. Enhanced accumulation of harpagide and 8-O-acetyl-harpagide in Melittis melissophyllum L. agitated shoot cultures analyzed by UPLCMS/MS. PLoS ONE 2018, vol.13, e0202556.

[20] PIETRASZEK, J. Response surface methodology at irregular grids based on Voronoi scheme with neural network approximator. In 6th International Conference on Neural Networks and Soft Computing. Zakopane, Springer, 2003, pp.250-255. 